Forthcoming Review of International Economics

\title{
The Balassa-Samuelson Model: An Overview
}

\author{
Patrick K. Asea \\ University of California, Los Angeles \\ W. Max Corden \\ The Johns Hopkins University
}

March 25, 1994

Working Paper \# 710

"This special issue is dedicated to the memory of Bela Balassa whose death in May 1991 deprived the profession of an outstanding researcher and inspiring teacher. We are grateful to Anusha Chari, Federico Sturzenegger and contributors to the special issue for valuable comments and suggestions. Any errors and omissions are our joint responsibility. Correspondence to: Patrick K. Asea, Assistant Professor, Department of Economics; University of California, Los Angeles; 405 Hilgard Avenue, Los Angeles CA 90024. Internet: asea@sscnet.ucla.edu 


\title{
The Balassa-Samuelson Model: An Overview
}

\begin{abstract}
This paper introduces a special issue marking the thirtieth anniversary of the publication of two classic papers in international economics, Balassa (1964) and Samuelson (1964). We provide a brief analytical treatment of the basic model and an overview of the contributions in this special issue. The papers include novel empirical and theoretical approaches related to the Balassa-Samuelson model. Theoretical models include dynamic two-sector growth models, two-country general equilibrium models and open-economy models with imperfectly competitive nontraded goods sectors. Several papers exploit new sources of data or datasets constructed in new ways from traditional sources.
\end{abstract}

Keywords: Real Exchange Rates, Productivity Differentials, Tradables, Nontradables.

JEL Classification System: F41 (Macroeconomic Aspects of International Trade and Finance) 
"Under the skin of any international economist lies a deep-seated belief in some variant of the PPP theory of exchange rates." [ Rudiger Dornbusch \& Paul Krugman 1976, p.540 ]

\section{Prologue}

It is well known that the exchange rate, which is arguably the single most important price in an open economy, is intimately related to the concept of purchasing power parity (PPP). PPP is a theory of exchange rate determination, is widely used in policy-making deliberations and serves as a conversion factor in transforming currency values from one denomination to another. However, despite the widespread use of PPP in exchange rate issues, the relationship between the two is the subject of heated debate. Consequently, PPP and real exchange rate issues, remain central research topics in international economics.

This special issue marks the thirtieth anniversary of the publication of two classic articles in international economics, The Purchasing Power Parity Doctrine: A Reappraisal, by Bela Balassa and Theoretical Notes on Trade Problems by Paul Samuelson. Widely referred to as the Balassa-Samuelson model, these two articles provide the canonical frame of reference for discussing links between PPP, exchange rates and inter-country real income comparisons. This special issue brings together a collection of articles that evaluate the legacy of these seminal articles and highlight the state-of-the-art in international economics related to the Balassa-Samuelson model.

Balassa [1964] and Samuelson [1964] independently provided what has come to be regarded as the definitive explanation of why the absolute version of PPP is flawed as a theory of exchange rates. ${ }^{1}$ The absolute version of PPP relies on spatial arbitrage in an integrated, perfectly competitive world economy to equalize the relative prices (in different currencies and locations) of a common basket of goods when quoted in the same currency.

To illustrate this, let $p_{i}$ and $p_{i}^{\star}$ represent the price of the ith good at home and abroad respectively. Define the exchange rate, $e$, as the number of units of domestic currency per unit of foreign currency. Let $P$ and $P^{\star}$ be the aggregate price level at home and abroad quoted in their respective currencies. Consider a domestic price index $P=$ $h\left(p_{1}, \ldots, p_{i}, \ldots, p_{n}\right)$ and a foreign price index $P^{\star}=f\left(p_{1}^{*}, \ldots, p_{i}^{*}, \ldots, p_{n}^{*}\right)$. 
Absolute PPP holds if in the absence of all frictions the prices of each good in domestic currency are equalized across countries. If the same goods enter each country's market basket with identical weights then the law of one price extends to aggregate price levels, yielding, $e=$ $P / P^{\star}$.

The absolute version of PPP therefore predicts that in the absence of all frictions the prices of a common basket of goods in the two countries measured in a common currency will be the same at all times, i.e., $P / e P^{*}=1$. Balassa and Samuelson identified an important factor that introduces systematic biases into the relationship between exchange rates and relative prices. The crux of their analysis was identifying productivity growth differentials between the tradable and nontradable sectors as instrumental in altering a country's internal price structure.

Balassa and Samuelson argued that a high income country is technologically more advanced than a low income country. Yet the technological advantage is not uniform across sectors. The technological advantage of the high income country is greater in the tradable sector than in the nontradable sector. By the law of one price, the prices of tradable goods will be equalized across countries. However, this would not be the case in the nontradables sector, where the law of one price does not hold. Increased productivity in the tradable goods sector will increase real wages and as a result lead to an increase in the relative price of nontradables. Long-run productivity differentials would thus lead to trend deviations from PPP.

Balassa and Samuelson also examined the effect that deviations of exchange rates from PPP have on inter-country income comparisons. Balassa provided empirical evidence that the real price structure of a large group of countries shows a systematic correlation with the level of per-capita income. In particular, the lower the per-capita income of a country the lower the domestic price of services. This reasoning runs counter to the predictions of the absolute version of PPP that states that exchange rate conversions based on PPP yield unbiased income comparisons.

The results of both papers hinge on two powerful insights. The first, is that the introduction of nontradables into standard trade models was necessary to understand the relationship between exchange rates and relative prices. The second is (the empirically verifiable fact) that productivity differentials between the tradable and nontradable sectors introduce systematic biases into the PPP-exchange rate rela- 
tionship. While neither of these insights was exactly novel, the 1964 papers are widely regarded as the fundamental papers in the area. ${ }^{2}$ In our opinion, this is not only because Balassa and Samuelson provided the clearest theoretical articulation of why exchange rates deviated from PPP, but also because in showing that the deviations were systematically linked to productivity differentials they traced out the implications of such deviations for international real income comparisons and provided compelling empirical evidence to support the theory. ${ }^{3}$

The papers in this issue fall into three interrelated groups. The first group of papers by Paul Samuelson and Alan Heston, Daniel Nuxoll \& Robert Summers consist of work related to inter-country real income comparisons. Next, is a pair of papers by Patrick Asea \& Enrique Mendoza and Philip Brock that is unified by their focus on examining the implications for the relative price of nontradables of integrating demand-side considerations into the Balassa-Samuelson framework. Finally, the third set of papers; by Alberto Giovannini, Jose DeGregorio \& Thomas Krueger and Philip Brock \& Stephen Turnovsky draw on and extend the dependent economy model in a number of significant ways.

The rest of the paper is organized as follows. Section 2 outlines the basic analytical framework. Section 3 reviews the contributions of the papers in the special issue. Section 4 provides some concluding remarks

\section{The Original Model}

In this section we briefly outline the essential features of the basic model as developed in Balassa [1964]. ${ }^{4}$ The original treatment was in terms of a traditional Ricardian trade model amended to include nontradable goods. ${ }^{5}$ Balassa assumed a two-country, two commodity world with one scarce factor, labor, and constant input coefficient technology. To illustrate the basic propositions of the Balassa-Samuelson model we recast the model in a more general setting. ${ }^{6}$

Consider a small open economy that uses capital and labor to produce tradable goods $(T)$ priced in world markets and nontradables $(N T)$ priced in the domestic market. Both capital $(K)$ and labor $(L)$ are perfectly mobile across sectors domestically. Labor is immobile between countries whereas capital is perfectly mobile internationally. 
The economy is assumed to be at full employment

$$
L=L_{T}+L_{N}
$$

where $\left(L_{T}\right)$ is labor in the tradable sector and $\left(L_{N}\right)$ is labor in the nontradable sectors.

Production of tradables and nontradables requires inputs of capital $\left(K_{T}, K_{N}\right)$ and labor $\left(L_{T}, L_{N}\right)$. Technology is characterized by linear homogeneous production functions in each sector.

$$
Y_{T}=\theta_{T} K_{T}^{\beta_{T}} L_{T}^{\alpha_{T}} \equiv \theta_{T} L_{T} f\left(k_{T}\right)
$$

and

$$
Y_{N}=\theta_{N} K_{N}^{\beta_{N}} L_{N}^{\alpha_{N}} \equiv \theta_{N} L_{N} f\left(k_{N}\right)
$$

where $Y_{T}, Y_{N}$ are output in the tradable and nontradable sectors respectively, $k_{T} \equiv K_{T} / L_{T}$ and $k_{N} \equiv K_{N} / L_{N}$ and $\theta_{T}, \theta_{N}$ are stochastic productivity parameters.

The small open economy takes the world interest rate, $i$, as given. With perfect competition the world interest rate equals the value of the marginal product of capital in each sector

$$
\begin{gathered}
i=\theta_{T} \beta_{T} k_{T}^{\left(\beta_{T}-1\right)} \\
i=s \theta_{N} \beta_{N} k_{N}^{\left(\beta_{N}-1\right)}
\end{gathered}
$$

where $s=P^{N} / P^{T}$ is the relative price of nontradables (the real exchange rate).

The capital-labor ratio in tradables $\left(k_{T}\right)$ is determined by (4). The neoclassical theory of factor prices as summarized in the factor price frontier is useful in solving for the tradables wage. With two factors of production the factor price frontier can be obtained by the maximization of profit $(F(K, L)-w L-r k)$ which generates factor demand functions in each sector. Then the assumption of linear homogeneity enables the wage rate in the tradable sector to be represented by:

$$
\begin{aligned}
w & =\theta_{T}\left[f\left(k_{T}\right)-f^{\prime}\left(k_{T}\right) k_{T}\right] \\
& =\theta_{T}\left(1-\beta_{T}\right) k_{T}^{\beta_{T}} .
\end{aligned}
$$

since $f^{\prime \prime}(k)<0$ the wage is an increasing function of $k, i=f^{\prime}(k)$ is therefore a decreasing function of $k$. Hence, $w$ and $i$ reduce to the factor 
price frontier, a downward locus on the $(w, i)$ plane with parameter $k$. Countless points exist on any particular factor price frontier. The one point that corresponds to the actual factor endowment in the economy is the neoclassical equilibrium. At that point all factors of production are fully employed.

Solving for $k_{T}$ from (5) and substituting in (7) yields the wage equation

$$
\begin{aligned}
w & =\theta_{T}\left(1-\beta_{T}\right)\left(\theta_{T} \beta_{T} / i\right)^{\frac{\beta_{T}}{1-\beta_{T}}} \\
& =\left(1-\beta_{T}\right)\left(\theta_{T} \beta_{T} / i\right)^{\frac{\beta_{T}}{1-\beta_{T}}}
\end{aligned}
$$

Which brings us to the first important point: in a small open economy, the wage $(w)$ is determined entirely by factor productivity in tradables.

Solving for the capital-labor ratio in nontradables from (5) yields

$$
k_{N}=\left(s \theta_{N} \beta_{N} / i\right)^{\frac{1}{1-\beta_{N}}}
$$

Perfect competition in the nontradables sector requires that the following condition hold

$$
s \theta_{N} f\left(k_{N}\right)=i k_{N}+w
$$

Then from (3), (7) and (8) and for given $i$ the relative price of nontradables is

$$
\begin{aligned}
\hat{s} & =\alpha_{N} \hat{w}-\hat{\theta}_{N} \\
\hat{s} & =\frac{\alpha_{N}}{\alpha_{T}} \hat{\theta}_{T}-\hat{\theta}_{N}
\end{aligned}
$$

where a hat above a variable denotes a rate of percentage change.

The second important point is apparent from (10): the relative price of nontradables depends on the productivity differential in the tradable and nontradable sectors. These two points are summarized in the following proposition:

Proposition 1 (Balassa 1964 ) The greater are productivity differentials in the production of tradable goods between countries, the larger will be differences in wages and in the prices of services and correspondingly the greater will be the gap between purchasing power parity and the equilibrium exchange rate. 
Proposition 1 highlights two basic predictions of the Balassa-Samuelson model, namely: (i) productivity differentials determine the domestic relative price of nontradables and (ii) deviations from PPP reflect differences in the relative price of nontradables. This proposition captures the essence of the Balassa-Samuelson model. Movements of the relative price of nontradables reflect divergent trends of productivity between tradable and nontradable goods. To illustrate this, from (10), consider an increase in $\theta_{T}$ holding $\theta_{N}$ constant for fixed $i$. It is clear that this will lead to an increase in the real wage and subsequently an increase in the relative price of nontradables.

\section{The Special Issue}

\section{A. Inter-Country Real Income Comparisons}

The Balassa-Samuelson model provides an important framework for understanding the relationship between exchange rates and intercountry real income comparisons. This aspect of the Balassa-Samuelson model is summarized in the following proposition:

Proposition 2 (Balassa 1964 ) If international productivity differences are greater in the production of tradable goods than in the production of nontradable goods, the currency of the country with the higher productivity will appear to be overvalued in terms of purchasing power parity. Therefore the ratio of purchasing power parity to the exchange rate will be an increasing function of income.

Proposition 2 has proven important in the work of the United Nations International Comparisons Program (ICP). Among other important facts, the ICP has provided evidence that in comparing rich and poor countries, the richer country will be estimated to be richer than it really is if the absolute version of PPP is used as a conversion factor. ${ }^{7}$ The low relative price of nontradables in poor countries, makes their true purchasing power significantly above what exchange rateconverted income suggest. The ICP researchers have also documented that the higher the per-capita income of a country, the higher the price of services in it.

In the lead article, Facets of Balassa-Samuelson Thirty Years Later, Paul Samuelson provides an insightful evaluation of the empirical facts 
documented by the ICP researchers and the variety of theoretical rationalizations that have attempted to explain these facts. Samuelson refers to the empirical facts documented by the ICP researchers as the "Penn-effect" i.e, the tendency for real income comparisons based on PPP's to be systematically biased.

In evaluating the theoretical explanations that have been provided for the Penn-effect Samuelson traces the seeds of the Balassa-Samuelson model to the early writings of Roy Harrod (1957) and David Ricardo (1911) ${ }^{8}$ He notes that the Balassa-Samuelson model is one of several "theoretical rationalizations" of the empirical facts documented by the ICP researchers. Bhagwati (1984) and Kravis \& Lipsey (1983) have provided an important alternative explanation for the Penn-effect. Bhagwati (1984) argues that the adoption of more capital-intensive manufacturing techniques as countries develop, rather than exogenous technological progress, can explain the increase in the relative price of nontradable goods. In evaluating Bhagwati's (1984) explanation, Samuelson shows that it requires much stricter conditions than the Balassa-Samuelson-Harrod-Ricardo explanation. Therefore, the more general Balassa-Samuelson-Harrod-Ricardo explanation is preferred. Bhagwati's contribution therefore lies in providing additional important sufficient conditions under which the Penn-effect would be expected to hold.

Samuelson notes that while the Penn-effect is an important empirical fact, it is unlikely that any single theory or set of conditions alone can explain it. To prove this point Samuelson provides a carefully worked out series of theoretical and numerical examples. The examples confirm the Penn-effect but show that it is possible to have a Penn-effect in the absence of productivity differentials. This finding underscores the fragility of the Ricardo-Harrod-Balassa-Samuelson explanation. Samuelson argues that the reason for the fragility of the theoretical explanation lies in understanding the Penn-effect as an implication of correct index-number theory. He concludes by noting that "exchange rate conversions are unsound algorithms in index-number theory". This statement is strikingly similar to his earlier statement " PPP is a misleadingly pretentious doctrine, promising us what is rare in economics, detailed numerical predictions." Samuelson [1964, p.153].

The Balassa-Samuelson model is rich in empirical predictions. One important prediction is that because productivity growth is greater in 
tradables than in nontradables, the differential in nontradable productivity between rich and poor countries should be less than the differential in tradable productivity. This should lead to a greater difference between the price of nontradables relative to the price of tradables the poorer the country. In The Differential Productivity Hypothesis and Purchasing Power Parities: Some New Evidence, Alan Heston, Daniel Nuxoll and Robert Summers carefully examine the prediction that the difference between nontradable--tradable prices is greater the poorer the country. This prediction implies that poor countries' price levels will be lower than rich countries'.

The original evidence for the fact that countries' price levels are lower the lower their per-capita income was drawn from the Organization of European Economic Cooperation Studies of Gilbert \& Kravis (1954) and Gilbert \& et al (1958). Heston, Nuxoll and Summers extend previous research that used the 1970,1975 benchmarks to the more recent 1980,1985 benchmarks for a larger group of countries. The authors examine how well the Balassa-Samuelson model stands up across countries and time. The evidence they provide verifies that the difference between nontradable and tradable price parity changes with income as predicted by the Balassa-Samuelson model.

In providing new evidence to ascertain this fact the authors make an important contribution to the literature. A much overlooked but essential aspect of scientific research is the reexamination of previously discovered facts to evaluate the robustness of the original research findings. By subjecting an important prediction of the Balassa-Samuelson model to close empirical scrutiny the authors underscore the robustness of the Balassa-Samuelson model in explaining the stylized facts.

\section{B. Long-run and Demand-Side Factors.}

The original formulation of the Balassa-Samuelson model, in a $\mathrm{Ri}$ cardian framework, emphasized that the relative price of nontradables is influenced by microeconomic factors: endowments, tastes, technology and intertemporal savings and investment choices, i.e., long-run factors. This suggests that any useful theoretical treatment of the Balassa-Samuelson model should be based on microfoundations. The next two papers satisfy this requirement and contribute to the theoretical literature by highlighting the importance of demand-side considerations in explaining the evolution of the relative price of nontradables. 
In The Balassa-Samuelson Model: A General Equilibrium Appraisal, Patrick Asea \& Enrique Mendoza embed the static Balassa-Samuelson model in a dynamic general equilibrium setting in which tastes, technology and endowments are explicitly specified. The strength of this approach is that Asea \& Mendoza are able to derive two testable propositions of the Balassa-Samuelson model namely, that: (i) productivity differentials determine the domestic relative price of nontradables and, (ii) deviations from PPP reflect differences in the relative price of nontradables.

To test the predictions of the model, Asea \& Mendoza construct a cross--country sectoral panel database from existing OECD data. The authors argue that a compelling empirical investigation of the relationship between productivity differentials, real exchange rates and relative prices requires the separation of long-run trends from short term movements. They extract the long-run trends in the data with the Hodrick-Prescott filter.

In this important contribution, Asea \& Mendoza carry out a careful empirical examination of the Balassa-Samuelson hypothesis across countries and time. This is the first test of the predictions of the Balassa-Samuelson model that is based on a clearly specified dynamic equilibrium model. The empirical tests support the proposition that productivity differentials determine the relative price of nontradables. However the authors find little evidence to support the proposition that deviations from PPP reflect differences in the relative price of nontradables.

The limitations of the two-factor, two-good, general equilibrium model in explaining the evolution of the price of nontradables has led researchers to study three-factor models. In, Economic Development and the Relative Price of Nontradables: Global Dynamics of the Krueger-Deardorf-Leamer Model, Philip Brock extends the three-factor model to incorporate nontradables. Unlike much of the literature that assumes technological progress is exogenous, Brock endogenizes the process of capital accumulation, emphasizing the importance of investment and the choice of technique in determining the evolution of the relative price of nontradables.

Brock's key finding is that endogenizing forward-looking investment in the three-factor model of economic development produces bifurcations in the model's dynamics that do not occur when capital accumulation is exogenous. The two saddlepaths associated with the 
bifurcation display the characteristic that history, as embodied in the economy's capital stock as well as forward looking expectations determine whether the economy chooses the low investment or the high investment trajectory.

Brock shows how the relative capital intensity of nontradables switches in the model and provides a complete treatment of the global dynamics that emerges in this multi-sector framework. The global dynamics trace out movement from a region with a labor-intensive manufacturing technique to one with a capital-intensive manufacturing technique. Brock's results hinge on the assumption that the capital-producing sector (the nontradable sector) is intermediate in capital intensity relative to the two techniques for producing the manufactured good.

Brock's analysis provides the first global treatment of the dynamics of the three-factor model. His results show that the relative price of nontradables, is as much demand determined as supply determined during economic development. To the extent that the upper saddlepath of the model corresponds to empirical notions of a productivity mira$c l e$, the model suggests that the creation of mechanisms to coordinate expectations may promote structural change and economic growth.

\section{The Dependent Economy Model and Monopolistic Competition}

The Balassa-Samuelson model emphasizes the role of supply--side factors in determining the relative price of nontradables in long-run equilibrium. The dependent economy model developed in the work of Salter (1959), Swan (1960) and Corden (1960) emphasizes the role of short--run demand-side factors in determining the dynamics of the relative price of nontradables. ${ }^{9}$ Both approaches focus on fluctuations in the real exchange rate arising from movements in the relative price of nontradable goods by abstracting from the terms of trade (the small country assumption). Both models stress the distinction between tradables (exportable plus importables) and nontradables with imports and import competing goods assumed to be perfect substitutes. Therefore, with their relative prices given, exportables and importables (imports plus import substitutes) can be aggregated into one Hicksian composite good, referred to as the tradable.

The next two papers draw upon features of both the dependent economy model and the Balassa-Samuelson model to enhance our un- 
derstanding of the evolution of nontradable goods prices and the appropriate treatment of investment in the dependent economy model. "The Behavior of Nontradable Goods Prices in Europe: Evidence and Interpretation," by Alberto Giovannini, Jose DeGregorio and Thomas Krueger is motivated by the observation that for several European countries the relative price of tradables has appreciated over the 19751990 period yet the appreciation has not been uniform across countries or time. This suggests that the appreciation of the real exchange rate is not due to a single common external factor but to country-specific factors.

To investigate the causes of the appreciation of the real exchange rate, Giovannini, DeGregorio and Krueger develop a two-sector, small open economy model in which nontradable goods are produced by monopolistically competitive firms. Government expenditures are in the form of nontradable goods and wages are determined by a centralized labor union. An important aspect of the paper is the incorporation of imperfectly competitive labor markets in an open-economy macro model. This is an important consideration because the typical assumption in open-economy models of perfectly competitive labor markets is inconsistent with the empirical facts in Europe. The authors show that in their model shocks to productivity, consumer tastes, government expenditures and the price of tradables affect labor demand, wages and ultimately the relative price of nontradables goods.

The empirical evidence supports this modified Balassa-Samuelson model. The evidence suggests that demand shifts in the private sector as well as faster productivity growth in the tradable sector are important factors in explaining the appreciation of the real exchange rate in Europe. The authors also provide evidence of the slow adjustment in the price of nontradables. They attribute the slow adjustment to a lack of credibility that places pressure on target real wages.

Despite the natural link between the dependent economy model and the Balassa-Samuelson model researchers have failed to fully integrate the two models in a meaningful way. This is primarily due to the unsatisfactory treatment of investment expenditures in dependent economy models. Dynamic extensions of the dependent economy model have rested on strict assumptions on whether investment is tradable or nontradable and also on whether the tradable sector is more or less capital-intensive than the nontradable sector.

In the "Dependent Economy Model with both Tradable and Non- 
tradable Capital Goods," Philip Brock \& Stephen Turnovsky introduce investment into the dependent economy model in an attempt to resolve some of these difficulties. Brock and Turnovsky assume a production structure with three factors: nontradable capital (structures), tradable capital (equipment) and labor. They find that with endogenous investment it is the relative sectoral intensity of nontradable capital that matters for the dynamic adjustment of the relative price of nontradables. The relative sectoral intensity of tradable capital primarily affects the adjustment of the capital account.

Brock \& Turnovsky resolve the controversy over the appropriate manner to treat investment in optimizing models with nontradable goods. The controversy has made every specification appear to be "fragile" in the sense that results are highly sensitive to different assumptions regarding capital intensity and the use of tradable and nontradable capital. The authors show that the dynamic adjustment of the relative price of nontradables in the dependent economy model is primarily driven by the nontradable capital stock. Tradable capital is important as an additional influence on the behavior of the current account.

Earlier attempts at incorporating both tradable and nontradable capital in the production structure have failed because of the mathematical complexity of the problem. Brock \& Turnovsky's efforts at finding an analytically tractable solution with both types of capital constitutes a significant contribution to the literature.

\section{Concluding Comments}

The studies that follow are diverse. They address a wide range of issues from traditional concerns to the implications of very recent theoretical work. Despite the diversity in approaches, all the papers in this special issue are concerned with explaining and evaluating important empirical facts. To quote Samuelson (1994)

"A reliable fact that is not provided with an explanation is better than a nice theory that helps explain and understand an untrue fact ... a reliable fact with a good theory to explain it is best of all--for the reason that experience suggests that it will more likely stay reliable..." 
Several papers in this special issue provide ample new evidence that the empirical regularities noted by Balassa-Samuelson-Harrod-Ricardo are reliable facts. A number of papers also point out the limitations of the theoretical explanations that have been provided for this fact (including the Balassa-Samuelson model itself). Notwithstanding the limitations of the theory, the main message remains, the theory as propounded by Balassa and Samuelson is useful in explaining longrun trend deviations from PPP and a wide variety of related economic phenomena. ${ }^{10}$ These papers will serve as important points of departure for future research, both empirical and theoretical. 


\section{References}

Balassa, Bela, "The Purchasing Power Parity Doctrine: A Reappraisal," Journal of Political Economy 72 (1964):584-96.

Bhagwati, Jagdish, "Why Services are Cheaper in Poor Countries," Economic Journal 94 (1984):279-86.

Corden, w. Max, "The Dependent Economy Model of the Balance of Payments," in The New Palgrave Dictionary of Money and Finance London, Macmillian 1992: 628-30.

"The Geometric Representation of Policies to Attain Internal and External Balance," Review of Economic Studies 28 (1960): 1-22.

Dornbusch, Rudiger and Krugman, Paul, "Flexible Exchange Rates in the Short Run," Brookings Papers on Economic Activity 3 (1976):537-75.

Gilbert Milton and Irving Kravis, An International Comparison of National Products and the Purchasing Power of Currencies, Paris: OEEC, 1954.

, and Associates, Comparative National Products and Price Levels Paris: OEEC, 1958.

Harrod, Roy F., International Economics, Cambridge Economic Handbooks. London: Nisbet and Cambridge University Press, 1933. Second edition, Chicago: The University of Chicago Press, 1957.

Kravis, Irving and Robert E. Lipsey, Towards an Explanation of National Price Levels Princeton Studies in International Finance, No. 52, 1983.

, Alan Heston, and Robert Summers, International Comparisons of Real Product and Purchasing Power Baltimore: Johns Hopkins University Press. 1978

and "The Share of Services in Economic Growth," in F.G

Adams and B. Hickman (eds.), Essays in Honor of Lawrence R. Klein, MIT Press, Cambridge, MA. 1983.

and

World Product and Income: International Comparisons of Real Gross Product Baltimore: Johns Hopkins University Press. 1982.

McKinnon, Ronald I, "Monetary Theory and Controlled Flexibility in the Foreign Exchanges," Essays in International Finance, International Finance Section, Princeton University, No. 84, 1971.

Officer, Lawrence, "The Purchasing Power Parity Theory of Exchange Rates: A Review Article" International Monetary Fund Staff Papers 23 (1976):1-60.

Ricardo, David, The Principles of Political Economy and Taxation London: J.M Dent and Sons, 1911.

Salter, W.E.G, "Internal and External Balance: The Role of Price and Expenditure Effects" Economic Record 35 (1959):226-38.

Samuelson, Paul, "Theoretical Notes on Trade Problems," Review of Economics and Statistics 23 (1964):1-60.

Samuelson, Paul, "Facets of Balassa-Samuelson Thirty Years Later" Review of International Economics 2 (1994) this issue.

Swan, Thomas W., "Economic Control in a Dependent economy," Economic Record 
36 (1960):51-66.

Obstfeld, Maurice, "Model Trending Real Exchange Rates," Working paper No. C93-011 (Center for International and Development Fconomics Research, University of California Berkeley) (1993). 


\section{Endnotes}

1. See Officer (1976) for an excellent survey of PPP.

2. The seeds of the Balassa-Samuelson model can be found in the writings of David Ricardo [1911] and Roy Harrod [1939]. Further, the use of nontradable goods in modern international economics dates from Swan (1960) and Salter (1959).

3. McKinnon [1971] reached the same conclusions, independently, in a study that was published several years after Balassa [1964] and Samuelson [1964].

4. Our treatment will focus on the derivation of the productivity-differential hypothesis and is similar to Obstfeld's (1993) treatment. See Kravis Heston \& Summers (1983) for an algebraic treatment of a related aspect of the Balassa-Samuelson model: why the price of services is so low in developing countries.

5. Both Balassa and Samuelson refer to the nontraded goods as services.

6. While Balassa's model is couched in terms of a single factor of production, he notes that it is straightforward to extend the model to allow for multiple factors of production.

7. See, Kravis, Heston and Summers (1978, 1982, 1983).

8. This was unknown by either Balassa or Samuelson at the time of writing these articles (Samuelson 1994).

9. See Corden (1992) for further details on the dependent economy model.

10. We have abstracted from challenges to the Balassa-Samuelson model, see Officer (1978). 